\title{
BIM Studio - An Immersive Curricular Tool for Construction Project Management Education
}

\author{
V. Paul C. Charlesraj, Anil Sawhney, Manav Mahan Singh and Aiswarya Sreekumar \\ RICS School of Built Environment, Delhi NCR, India \\ E-mail: vpcharlesraj@rics.org, asawhney@rics.org, manav.mahan.singh@live.in and asreekumar@rics.org
}

\begin{abstract}
Present approach to education within most design, construction and built environment schools is reported to be fragmented. As the industry moves towards more collaborative and integrative paradigms, the education sector needs to start shaping the "pipeline" of graduates that can better fit the changes occurring in industry. This paper is an offshoot of an ongoing sponsored research project aims at addressing this issue in an effort to stay abreast with the development on the Building Information Modelling (BIM) front in the industry; especially in an emerging market such as India. The model that forms the core of the BIM approach is a smart, shared and computable three-dimensional model of the building or the civil engineering facility that helps in overcoming the shortcomings of the 2D paper-based approach.
\end{abstract}

The goal of this project is to formulate a curricular strategy that allows, in a flexible and scalable way, construction project management programs to utilize BIM in providing an integrative and immersive learning experience to its students. In order to formulate the proposed strategy, studio-based course is developed in which BIM models are utilized to integrate and synthesize learning from a number of construction project management courses. The objectives and learning outcomes of the proposed studio-based course are in sync with the existing program/course objectives.

Keywords -

Building Information Modelling; BIM Studio; Curricular Tool; Construction Project Management; Project Management Education

\section{Introduction}

Designing and constructing the built environment is a creative and collaborative process; making it knowledge intensive and generative. The present approach to education within most design, construction and built environment schools reflects the very same fragmentation that has been identified as problematic in the context of the industry. Many construction project management programs are based around teaching principles and practices that accentuate defined streams of study, and are therefore limited in the extent to which problem-based learning can be applied. Subsequently, construction students do not necessarily recognise how the separate streams of knowledge fit together at the time they undertake individual courses. In a combined sense, there is limited understanding about how each course intrinsically contributes to construction project management or how construction project management contributes to the overall objectives of the built environment. This has remained a dormant problem as long as the industry had not awakened to this type of fragmentation. As the industry moves towards more collaborative and integrative paradigms, the education sector needs to start shaping the "pipeline" of graduates that can better fit the changes occurring in industry; requiring it to look closely at the programs that are currently being offered.

This paper is an offshoot of an ongoing sponsored research project aims at addressing this issue in an effort to stay abreast with the development on the Building Information Modelling (BIM) front in the industry; especially in an emerging market such as India where BIM is currently in its "experimentation" phase as compared to the developed world, especially when the maturity and level of implementation is taken into account [1]. BIM is a model-driven approach to designing, constructing, operating and maintaining buildings and civil engineering facilities. The model that forms the core of the BIM approach is a smart, shared and computable three-dimensional model of the building or the civil engineering facility that helps in overcoming the shortcomings of the 2D paper-based approach. Among other things, it can have cost and work flow scheduling data linked to it. BIM is not simply a computer technology; it also involves strategies relating people and processes that allow the use of the technology. 
The goal of this project is to formulate a curricular strategy that allows, in a flexible and scalable way, construction project management programs to utilize $\mathrm{BIM}$ in providing an integrative and immersive learning experience to its students. In order to formulate the proposed strategy, studio-based course is developed in which BIM models are utilized to integrate and synthesize learning from a number of construction project management courses. The objectives and learning outcomes of the proposed studio-based course are in sync with the existing program/course objectives. Construction Pathway guides of the Royal Institution of Chartered Surveyors (RICS) is used to develop a mapping between competencies and objectives. It also involves in the development of a multi-layered vehicle for student and teacher engagement that can be progressively used from early to latter years of learning keeping BIM as the centrepiece of this engagement. BIM models of sample real-time projects that can be utilized in the studio setting have been developed. Simulations of a construction project using these models that closely resembles realistic conditions are carried out. Students have been asked to explore current technological possibilities for integrating project management data by learning the functionality of BIM software applications and applying them in various management processes in construction during the present semester to test the efficacy of the proposed methodology.

\section{Literature Review}

It has been observed that there has been significant research studies reported on the role of BIM in education in general and role of BIM in AEC education in particular, in addition to BIM education. A brief account of the same is presented in this section.

\subsection{BIM Education}

To realise the full potential of BIM in education or practice, there must be substantial effort in imparting the education on how to implement BIM. This involves in educating the students at various levels of education, specifically at the tertiary education with adequate level of competencies to successfully deliver BIM [2, 3, 4, 5, $6]$.

\subsection{BIM-driven Education}

The role BIM in enhancing the teaching-learning process in any field of study is immense [7, 8, 9, 10, 11]. It has been reported that there are significant issues and challenges in integrating BIM into education such as already existing requirements for graduation, the absence of room in curriculum for additional courses and lack of reference material \& established curricula [8]. There is also a significant need for training the educators as well as improving the BIM competencies of the learners with progressive learning [9]. It has been identified that there is a considerate mismatch in the technical characteristics of BIM curricula at universities and the process-oriented approach to BIM represented by the industry [10]. However, BIM-driven education resulted in improvement in productivity and promoted innovation [11].

There has been limited research efforts reported in the adoption of BIM-driven education in specific domains of built environment such as Architecture, Engineering and Construction.

\subsubsection{BIM in Architecture and Engineering Education}

It has been reported that a balance of both theoretical, practical and technical course contents, an engaging project brief with industrial relevance, a well-formed collaborative team can each play a part in enriching the student's BIM experience for design [12, 13]. Projectbased learning of design can be enhanced using BIM [14] It has been felt by the industry that an innovative design of collaborative curriculum by universities is required for successful integration of BIM in engineering education $[15,16]$. The skills gap as perceived by the industry can be closed through integration of the principles of BIM throughout the fabric of undergraduate courses in higher education [17].

\subsubsection{BIM in Construction Project Management Education}

The preliminary feedback from research efforts in BIM-driven CPM education is encouraging [6, 18, 19, 20 $21,22,23]$. It has been reported that the interactive and visual nature of the modules created with BIM engages a high level of spatial cognition and critical thinking among students [20]. The industry input and participation in the classroom environment will be of critical significance in continuing to move the curriculum forward to reflect thoroughly or even to exceed the current state of construction and help incorporate areas that have yet to benefit from the possibilities of the new BIM applications [21].

However, there were certain critical challenges identified that inhibits the benefits of BIM-driven CPM education. Some of the critical challenges that were identified are: level of knowledge required to use BIM software, lack of reference materials, and model development not following the construction sequence, lack of intelligent error detection and correction by the BIM software, limited choices of component databases, and acceptance by faculty \& accrediting bodies [18, 22]. 


\subsection{Summary}

It is quite evident from the literature review that there is a need to further investigate the adoption of BIM in the CPM education to overcome the issues \& challenges identified. Hence, as stated earlier, it has been decided to formulate a curricular strategy that allows, in a flexible and scalable way, construction project management programs to utilize BIM in providing an integrative and immersive learning experience to its students.

\section{BIM Studio}

With the aim of formulating the proposed strategy, a studio-based course is developed in which BIM models are utilized to integrate and synthesize learning from a number of CPM courses.

\subsection{Conceptual Framework}

A typical CPM program has got various core/optional courses related to construction engineering \& technology and general \& project management with class room/studio-based teaching and field work such as internship. The proposed BIM Studio is expected to facilitate most of the above means of teaching \& learning processes.

The conceptual framework of BIM Studio is presented in Figure 1. Demonstration of various concepts of CPM through the models of real-time construction projects is the backbone of the proposed framework. It has been assumed that the models are created by BIM modellers and the roles of a CPM starts with the review of the models and subsequently prepare the models for construction planning, monitoring and control. Various lessons that are specific to a CPM function are created using multiple tools of BIM and these lessons are used by the learners through another set of tools.

In the process, the learning outcomes are assessed against the predefined learning objectives and/or any other standard for professional competence (in this case the RICS Assessment of Professional Competence with respect to construction and project management pathways [24] as presented in Table 1). The level of competency refers to: 1 - knowledge and understanding; 2 - application of knowledge and understanding; and 3 reasoned advice and depth of technical knowledge. These competencies are in turn mapped with various courses offered in a CPM graduate program.

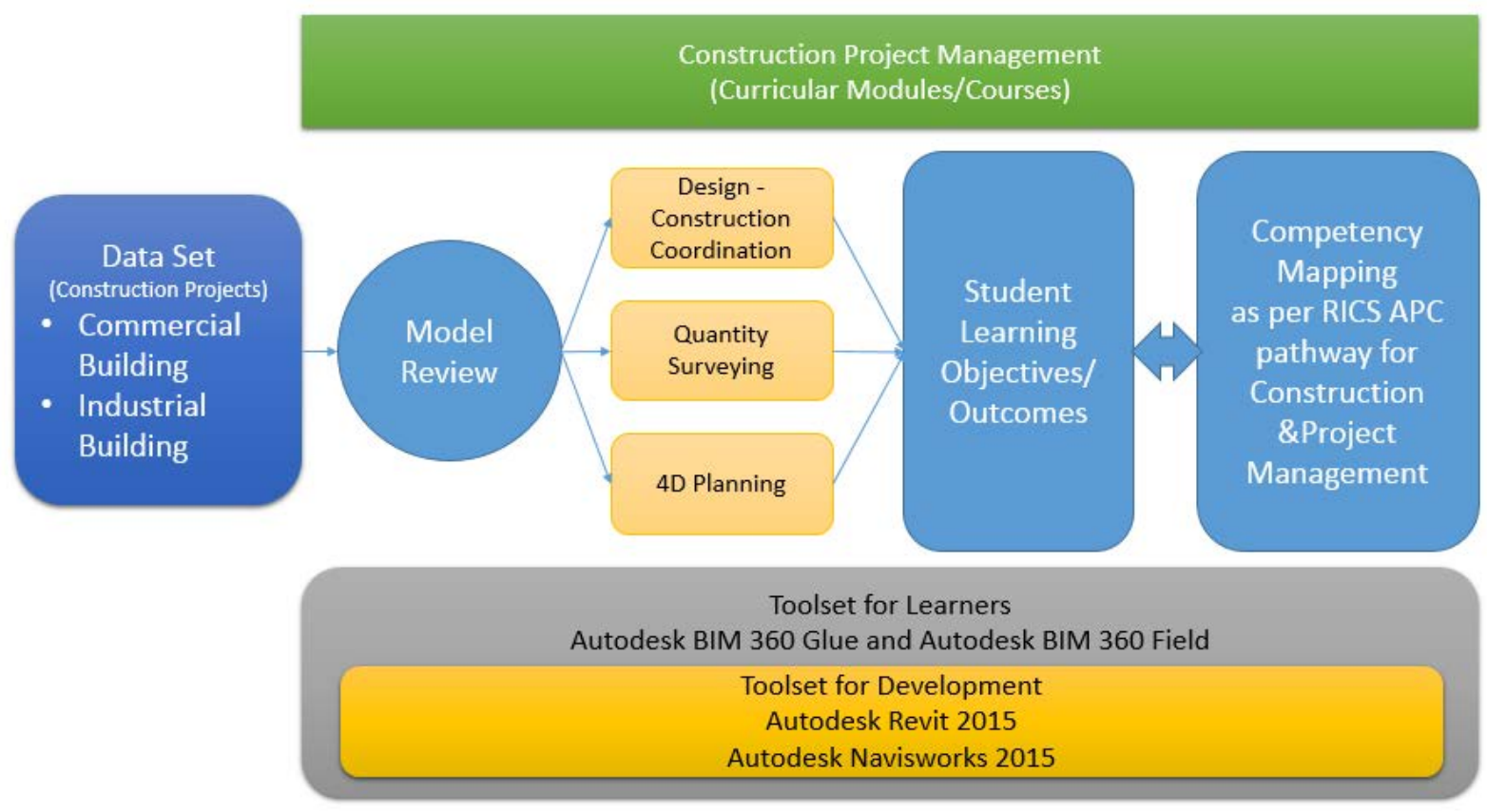

Figure 1 Conceptual Framework of BIM Studio 
Table 1 Competency Requirements for RICS Professional Qualification

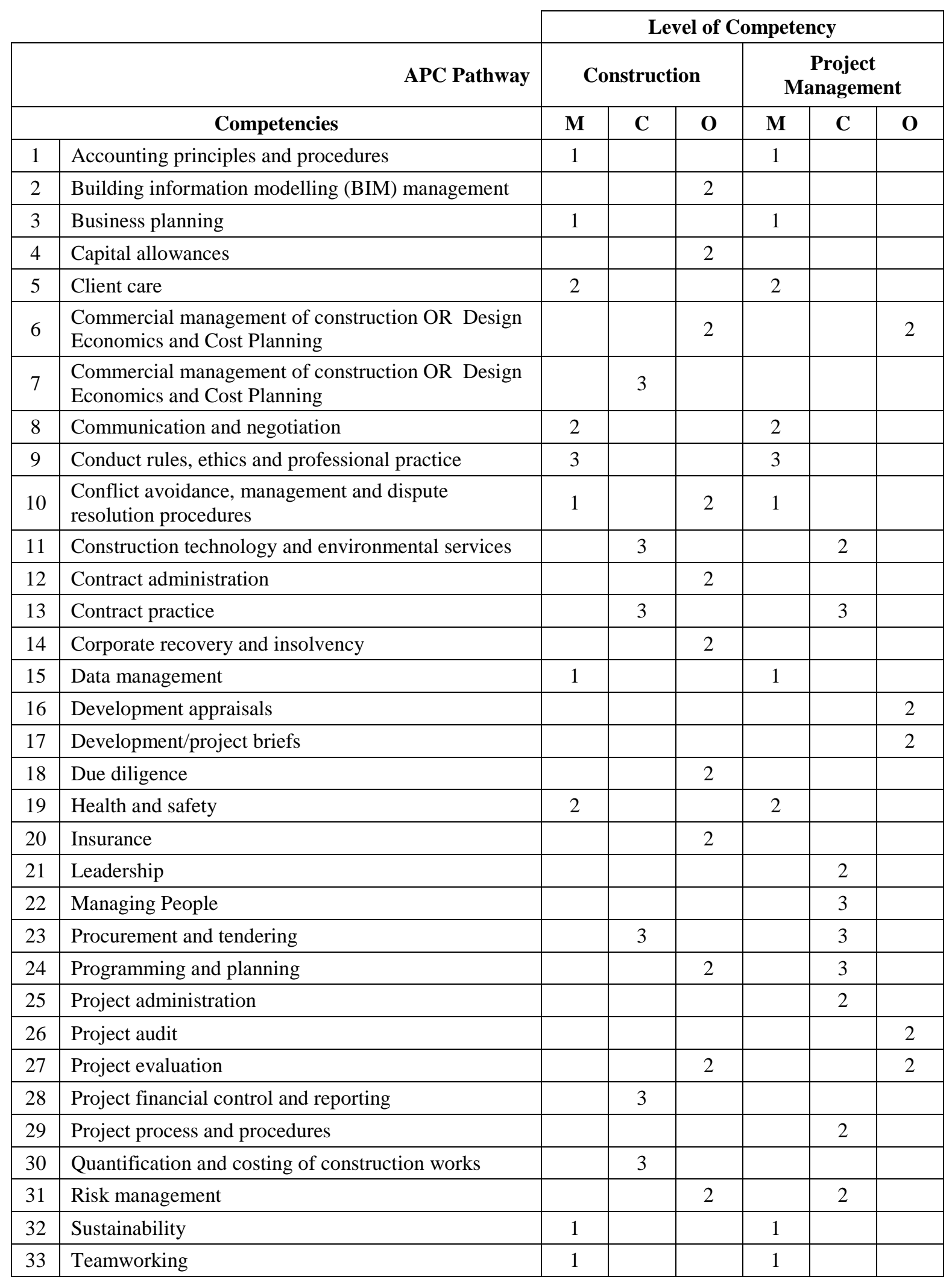

M-Mandatory C-Core $\quad$ O-Optional (Any Two for Construction \& any Three for Project Management) 


\subsection{Implementation}

\subsubsection{Models of Case Projects}

Composite BIM models of two real-time projects in India have been created. One of them represents a commercial building and the other one is of an industrial structure. Snapshots of the models are shown in Figure 2.

\subsubsection{Organisation of Lessons}

In order to organise the learning content in the proposed BIM Studio, a taxonomy as shown in Figure 3 is used. At present, there are six lessons in total in the
Studio namely: Review \& Mark-up, Clash Detection, Working with Clash Detection Results, 4D Simulation \& Construction Planning and Model-based Cost Estimation. There are various exercises under each of these lessons with exercise-specific learning objectives/outcomes as well as assessment guidelines. Every exercise involves in a set of tasks/learnings that in turn have multiples steps to be performed with the help of various learning resources such as videos, datasets, software tools to be used, etc. Organiation of a typical exercise within the taxonomy of the BIM Studio is presented in Figure 4. These exercises can be administered in various courses of CPM for an immersive experience of learning.
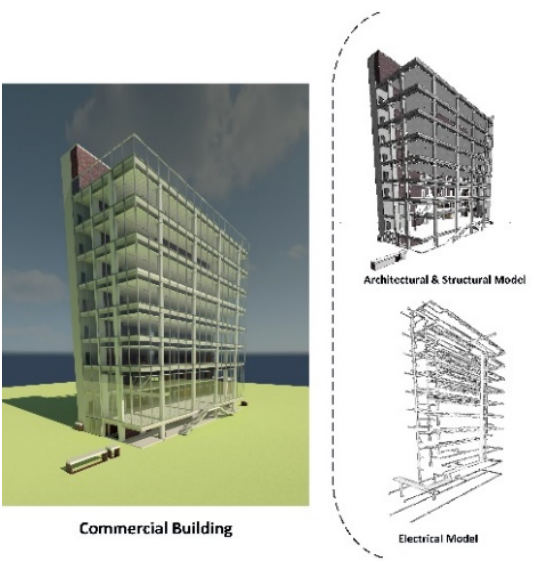

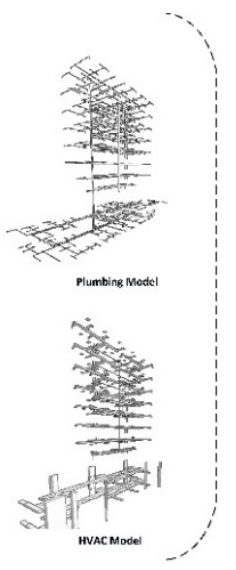

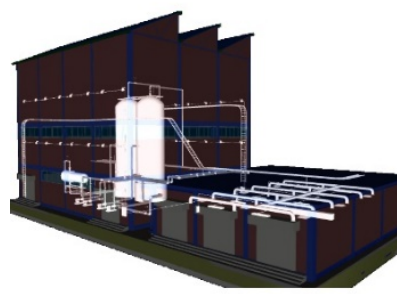

Industrial Building (Composite Model)

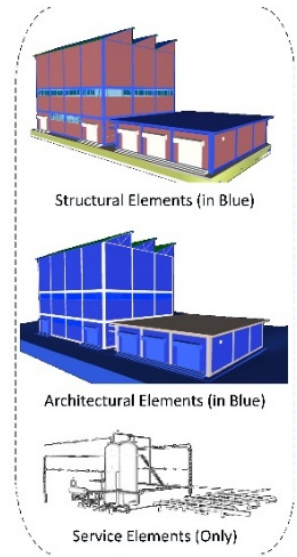

Figure 2 Composite Models of Commercial and Industrial Buildings

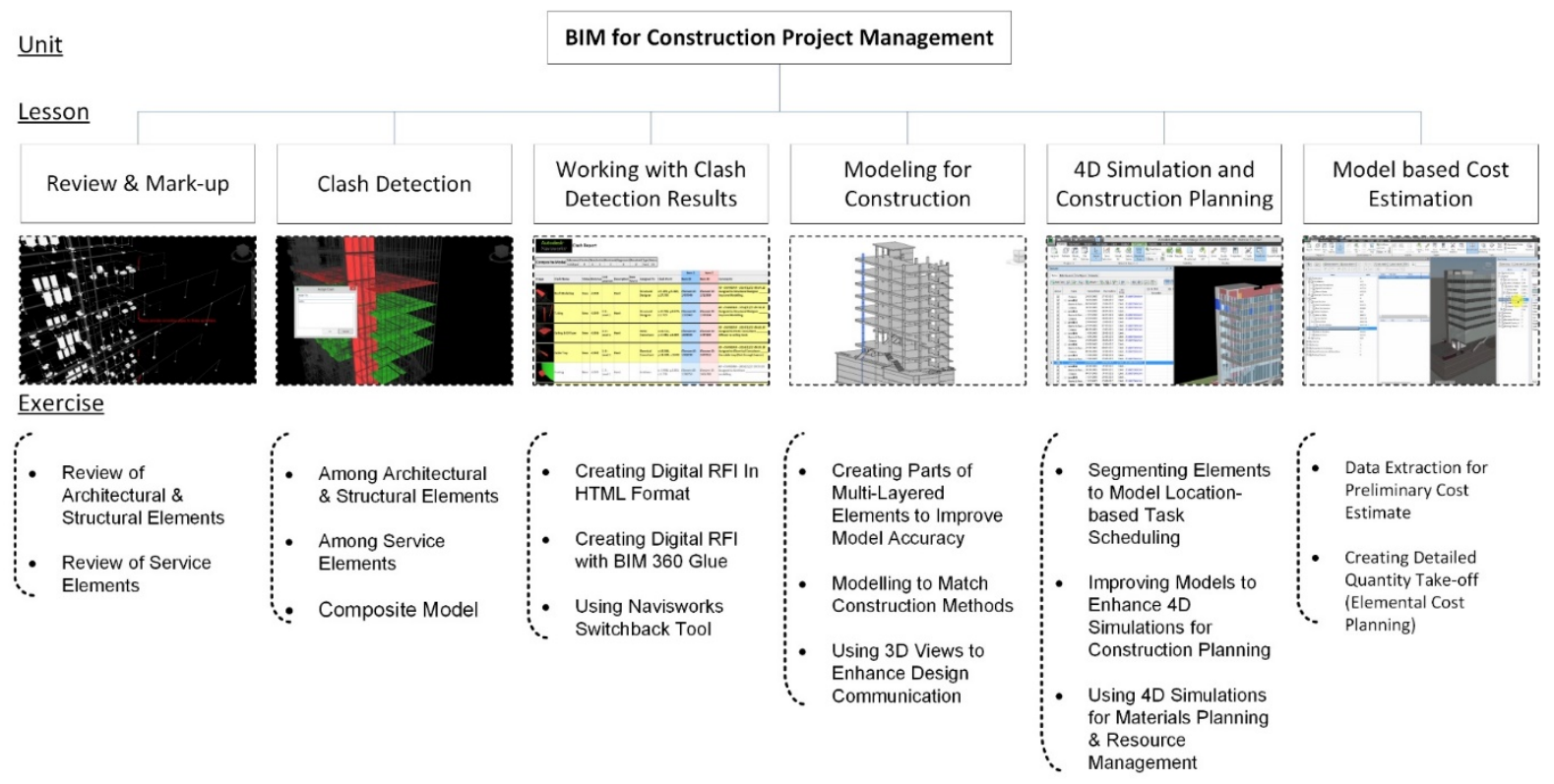

Figure 3 Taxonomy used in the BIM Studio 


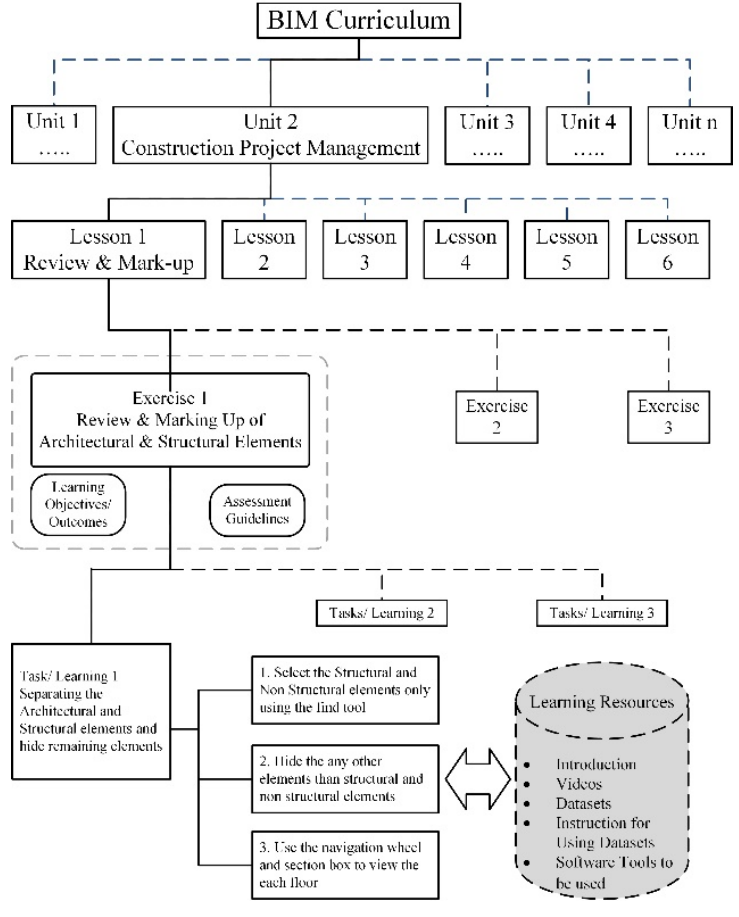

Figure 4 Organisation of a Typical Exercise in BIM Studio

\subsection{Testing}

The learning content developed under this BIM Studio project has been tested with a group of 34 students who are learning a course called "Construction Modelling and Simulation” as a pilot study. These students are undergoing a graduate program, MBA in CPM at RICS School of Built Environment, India. Program structure of this MBA in CPM is shown in Figure 5. It is a four semester program with various core and elective courses are distributed across all the four semesters. The courses in italics are non-teaching credit courses. It may be noted that the course in which the pilot study has been conducted is an elective course in the fourth semester. This implies that majority of the domain knowledge of CPM has been already imparted to these students through various teaching \& non-teaching courses.

This group of students have come from various backgrounds such as civil engineering (70\%), mechanical engineering (6\%), electrical \& electronics engineering(6\%), architecture (6\%), business administration (6\%), Information Technology (3\%) and Physics (3\%). 82\% of these students are fresh graduates and the remaining $18 \%$ have the work experience ranging from 7-60 months in the industry. They are generally having no (30\%) or little orientation (70\%) to BIM.

A set of six lessons have been administered ranging from model review to model-based cost estimation (including clash detection, quantity take-off and 4-D simulation). Students were familiarised with the models of the case projects in the very first session. Subsequently, every session was started with the introduction to the lessons on the learning objectives. This was followed by the screening of how-to videos that enabled the students to understand the entire process. Later, the tutor demonstrated the steps using the relevant tools. This was being followed by the students in parallel on their computers. Autodesk Revit and Navisworks were primarily used during this pilot run.

An online evaluation of the learning outcomes has been conducted in the form of multiple choice questions to assess the knowledge acquired as well as model-based testing for the assessment of skills. The test results were encouraging as more than $90 \%$ of students have learned the basic concepts of BIM and its application to CPM.

\subsubsection{Students' Feedback}

A feedback study that was conducted at the end of the sessions indicate that the overall response is encouraging as more than $70 \%$ students agreed that BIM Studio certainly improved their learning experience. It was also noted that there is a need for pre-training on application environment, familiar keywords and workspace. Shorter duration how-to videos were preferred over longer duration videos with more number of steps to be performed in an exercise. It was also reported that the narration content can be improved with pauses between steps that can enhance the learning outcome. Visual effects and animation to point over the icons and tools are the vital point of this kind of learning and allows user to keep track on actions of the tutor. More than $80 \%$ of respondents agree that the exercises developed under the BIM Studio project shall also be helpful in understanding the concepts in CPM.

\section{Summary}

BIM Studio is an attempt to create an immersive learning platform and an associated curricular strategy in order to improve the learning experience of the students as well as to meet the changing industry requirements in the field of construction project management. This helped in overcoming the fragmented learning in CPM education and promotes collaborative learning. The initial feedback from the prospective stakeholders is encouraging and the prospects of improving the learning content as well as the adaptive curricular strategy shall enhance the utility of the BIM Studio in educating the young graduates to be successful in their career as construction project managers. 


\section{Program Structure of MBA in Construction Project Management}

\begin{tabular}{|c|c|}
\hline Semester 1 & Semester 2 \\
\hline Real Estate and Infrastructure Development & Financial Management for Built Environment \\
\hline $\begin{array}{l}\text { Management Process and Organizational Behaviour for Built } \\
\text { Environment }\end{array}$ & Research Methods for Built Environment \\
\hline Construction Economics & Construction Cost Management \\
\hline Stakeholder Management for Built Environment & Construction Informatics \\
\hline Accounting for Built Environment & Construction Project Planning and Control \\
\hline Design Management and Pre-Construction Planning & Services for Built Environment \\
\hline Construction Materials, Methods and Technology & $\begin{array}{l}\text { Field Work and Project Analysis - II: Time and Cost } \\
\text { Management }\end{array}$ \\
\hline \multicolumn{2}{|l|}{$\begin{array}{l}\text { Communication and Soft Skills for Built Environment } \\
\text { Field Work and Project Analysis - I: Project Development }\end{array}$} \\
\hline \multicolumn{2}{|c|}{ Industrial Training (Summer Internship) } \\
\hline Semester 3 & Semester 4 \\
\hline Sustainable Practices for Built Environment & Professional Practice and Ethics for Built Environment \\
\hline Construction Contracts - Practice and Management & Business Planning and Strategies for Built Environment \\
\hline Risk Management in Construction & Laws and Regulations in Construction \\
\hline Procurement and Supply Chain Management & Elective-III \\
\hline Quality, Health, Safety and Environment Management & Elective - IV \\
\hline Elective -I & Capstone Project \\
\hline Elective - II & \\
\hline Field Work and Project Analysis - III: Construction & \\
\hline Management & \\
\hline \multicolumn{2}{|c|}{ Electives } \\
\hline Management of International Projects & Integrated Project Delivery \\
\hline Real Estate Agency and Marketing & Advanced Principles of Sustainability \\
\hline Lean Practices in Construction Projects & Climate Change and Environmental Engineering \\
\hline Information Systems for Built Environment & International Practices in Measurements \& Contracts \\
\hline Urban Regeneration, Development and Finance & Dispute Avoidance and Resolution Systems in Projects \\
\hline Construction Modelling and Simulation & Corporate Real Estate \\
\hline Social Cost Benefit Analysis & Asset Management \\
\hline Environmental Impact Analysis & \\
\hline
\end{tabular}

Figure 5 Program Structure of MBA in CPM

\section{References}

[1] Sawhney, A. State of BIM Adoption and Outlook in India, RICS Research Report, 2014.

[2] Mcgovern, E., Behan, A. and Furlong, K. Geomatics and Developments in BIM Education in Ireland. Proceedings of the FIG Congress 2014, Kualalampur, Malaysia, June 16-21, 2014.

[3] Succar, B. and Sher, W. Competency Knowledgebase for BIM Learning. Proceedings of the $38^{\text {th }}$ Australasian Universities Building Education Association Conference (AUBEA2013), Auckland, New Zealand, 20-22 Nov, 2013.

[4] Rooney, K. BIM Education - Gobal - Summary Report 2013. NATSPEC Construction Information,
Sydney, 2014.

[5] Succar, B. BIM in Practice: BIM Education. Report of BIM Education Working Group, Australia, 2012.

[6] Forsythe, P., Jupp, J. and Sawhney, A. Building Information Modelling in Tertiary Construction Project Management Education: A Programmewide Implementation Strategy. Journal for Education in the Built Environment, 8(1): 16-34, 2013.

[7] Mcdonald, M. and Donohoe, S. How are the Educational Institutes of Ireland Embracing the Paradigm Shift towards BIM ? Proceedings of CITA BIM Gathering, 2013.

[8] Sabongi, F. The Integration of BIM in the Undergraduate Curriculum: an analysis of undergraduate courses. Proceedings of the 45th 
Annual Conference of ASC, 2009.

[9] Suwal, S., Jäväjä, P., Rahman, A. and Gonzalez, V. Exploring Bim-based Education Perspectives. Proceedings of the 38th Australasian Universities Building Education Association Conference, 2013.

[10] Andersson, N. BIM Adoption in University Teaching Programs - The Swedish Case. Proceedings of CITA BIM Gathering, 2013.

[11] Sah, V. and Cory, C. Building Information Modeling: An Academic Perspective. Technol. Interface Journal/Winter Spec., 10(2), 2009.

[12] Gu, N. and de Vries, B. Two Approaches to Implementing BIM in Architectural Curricula. Digital Physicality - Proceedings of the 30th eCAADe Conference, 39-48, 2007.

[13] Roehl, A. and Shannon, G. J. Implications of Building Information Modeling on Interior Design Education: The Impact on Teaching Design Processes. J. Arts Humanit., 2(4),32-37, 2013.

[14] Shen, Z., Jensen, W., Wentz, T. and Fischer, B. Teaching Sustainable Design Using BIM and Project-Based Energy Simulations. Educ. Sci., 2, 136-149, 2012.

[15] Panuwatwanich, K., Wong, M. L., Doh, J.-H., Stewart, R. A. and McCarthy, T. J. Integrating building information modelling (BIM) into Engineering education: an exploratory study of industry perceptions using social network data. Proceedings of the 2013 AAEE Conference, 2013.

[16] Mohsen, J. P. and Issa, R. R. BIM implementation in civil and construction engineering curricula. Proceedings of the $14^{\text {th }}$ International Conference on Computing in Civil and Building Engineering, 2012.

[17] Mcgough, D., Ahmed, A. and Austin, S. Integration of Bim in Higher Education: Case Study of the
Adoption of BIM Into Coventry University's Department of Civil Engineering , Architecture and Building. Proceedings of the Sustainable Building and Construction Conference (SB13), 394-403, 2013.

[18] Wong, K. A., Wong, K. F. and Nadeem, A. Building Information Modelling for Tertiary Construction Education in Hong Kong. Journal of ITCon, 16, 467-476, 2011.

[19] Wang, G., Liu, H. and S. Zhang. Research on a framework for a BIM-based construction engineering and project management education platform. World Trans. Eng. Technol. Educ., 12(1), 101-104, 2014.

[20] Clevenger, C. M., Ozbeck, M. E., Glick, S. and Porter, D. Integrating BIM into Construction Management Education. EcoBuild Proceedings of the BIM-Related Academic Workshop, Fort Collins, 2010.

[21] Maghiar, M., Jain, S. and Sullivan, J. G. Strategy to incorporate BIM curriculum in planning and scheduling classes.in 120th ASEE Annual Conference \& Exposition, 2013.

[22] Taylor, J.,Liu, J. and Hein, M. Integration of Building Information Modeling (BIM) into an ACCE Accredited Construction Management Curriculum. Proceedings of the 44th ASC National Conference, 2008.

[23] Yan, L. and Shirong, L. BIM Teaching Strategy for Surveying Students in China. Proceedings of the International Conference on Education Technology and Management Science, 937-940, 2013.

[24] RICS. APC Requirements and Competencies. Apr 2014. 